\title{
Presença de Florestan no IEA
}

\section{CARLOS GUILHERME MOTA}

$\mathrm{E}$

U PERGUNTO: INSTITUTO DE ESTUdOS AVANÇADOS? Avançados em quê??" Desse modo irônico e desafiador, o professor Florestan Fernandes abriu a conferência do mês que marcava a abertura, em nosso Instituto, de uma reflexão sobre o modelo autocrático-burguês no Brasil. Esse era também um momento muito especial na vida do sociólogo-historiador: pela vez primeira, pisava ele num tardio 1987 a sala do Conselho Universitário da USP, o colegiado principal de sua universidade. Após anos de ditadura e de mediocridades instaladas nos colegiados da instituição, finalmente o Conselho Universitário - ou, ao menos, o auditório de reuniões - recebia a figura maior das Ciências Humanas produzida por esta instituição. Mas a pergunta florestânica permaneceria no ar, valendo também para toda a universidade: para que serve um Instituto de Estudos Avançados ?...

Respondemos ao mestre: para criar, entre outras coisas, oportunidades e situações como aquela e receber o melhor de nossas inteligências. Permanece portanto a pergunta: para que servem a universidade, os departamentos, os museus, os institutos ? Serão todos avançados?

Naquela oportunidade, Florestan, já adoentado, proferiu uma longa aula, em pé, sobre a ambígua e complexa transição histórica para a democracia no Brasil, uma das mais longas da História Contemporânea. Sintetizou, atualizando, as teses que estão em seus livros clássicos $A$ revolução burguesa no Brasil e Poder e contrapoder na América Latina, além de idéias e hipóteses espalhadas em quase cinqüenta outras obras de sua autoria. Uma rotação de perspectivas, num exercício transdisciplinar. A sala do Conselho poucas vezes terá sido palco de uma reflexão original sobre nossa complexa História.

As ligações de Florestan com o IEA foram muito fortes. E sempre desafiadoras. Na primeira vez que esteve em nossa sede, ao abrir a porta principal, deparou-se com as três fotografias que adornam o ball de entrada: no alto, a de Caio Prado Júnior; mais abaixo, a de Mário de Andrade e, ao lado, menor, a de Sigmund Freud. Florestan não teve dúvida: "Eis aí: Caio, com seu desejo de ser popular; Mário, com sua aspiração a aristocrata. E Freud, para analisar os dois"...

O sociólogo respondia assim ao desafio que lhe fizéramos, anos passados, ao dizer-lhe que uma de suas poucas falhas era não ter muito senso de humor. Em verdade, tinha-o violento e incontido, e nem sempre o graduava com maestria. 
Com a maturidade, porém, o tom cáustico deu lugar a uma fina, suave sabedoria. Já perto do fim, Florestan era a imagem perfeita de um completo e sábio gentil-homem. No hospital, em junho de 1995, mantinha-se aprumado em seu belo robe de chambre, cuidando, dentro das limitadas possibilidades de suas condições fisicas e de um Hospital das Clínicas de uma USP gravemente abandonada, os cabelos e a face em boa apresentação. Cavalheiro, não esquecera de uma escapadela para comprar o presente de aniversário para seu amigo de sempre, Antonio Candido.

Deputado federal, soube utilizar-se do trabalho que nosso Instituto produzia, reunindo material sobre a Escola Pública, organizado e discutido sob a regência suave mas firme do professor Alfredo Bosi. Com efeito, um grupo brilhante e variado de educadores, que incluía seu ex-assistente, sociólogo e pedagogo, Celso Beisigel, fornecia material para vários parlamentares do Congresso Constituinte e mais autoridades, numa atitude que eu chamaria de ilustrada. Florestan soube captar aquele material e transformá-lo, com Bosi e colegas, em letra de lei. Alguns itens de nossa Constituição de 88, dos mais avançados, têm sua origem ou quando menos estímulo nas reuniões do IEA com Florestan. Ele foi o nosso deputado por excelência, entre tantos outros excelentes, vigorosamente ligado à defesa da Escola Pública.

Vale também registrar que acedeu em publicar nesta revista Estudos Avanfados seu discurso de recepção do título Honoris Causa concedido pela Universidade de Coimbra, em 1990, quando completava ela 700 anos. Constitui, seu discurso, peça forte e definitiva na história do pensamento socialista no Brasil. Ou melhor, no mundo afro-luso-brasileiro, como assim foi conceituado naquela oportunidade, em Coimbra, quando estudiosos de vários quadrantes se reuniram no Primeiro Congresso do Mundo Luso-Afro-Brasileiro de Ciências Sociais, tendo sido escolhido precisamente o sociólogo brasileiro para a homenagem tão cheia de símbolos (atas em Revista Critica de Ciências Sociais, Coimbra, junho 1991, $\mathrm{n}^{\circ}$ 32). Para saudá-lo, Coimbra escolheu o professor Boaventura de Souza Santos, um dos organizadores do encontro, ex-pesquisador visitante do IEA, preocupado com as novas formas de saber e imaginar o social, onde produziu seu importante livro Introdução a uma ciência pósmoderna (Ed. Graal).

Por que Florestan é tão importante para nós? Para um grupo-geração que despontava na viragem dos anos 50 para os 60 , a presença de Florestan Fernandes foi decisiva. Muitos ainda estávamos no colégio, geralmente em colégios do Estado. Havia também algumas boas escolas particulares, mas nós éramos do colégio do Estado... Nossos professores de filosofia, de história, de ciências naturais nos falavam de uma instituição nova e então muito combativa e avançada: a Faculdade de Filosofia. Nela, vários estudiosos com garra, divergentes e 


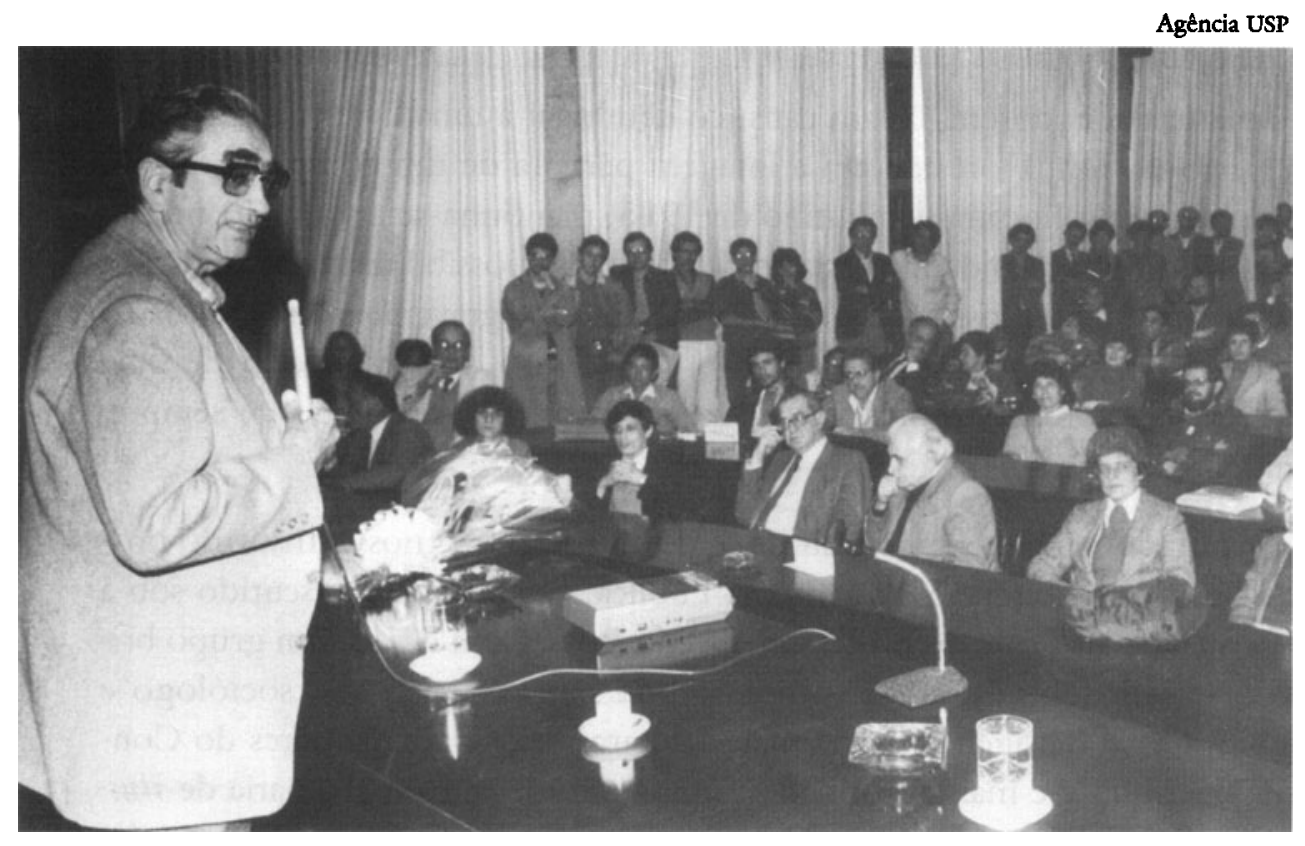

Florestan na Conferéncia do Mês do IEA na Sala do Conselho Unipersitario da USP em 1987

anticonvencionais aborreciam o establishment, a cultura estabelecida e as verdades acabadas. A simples expressão Faculdade de Filosofia nos encantava, a nós que já líamos as obras de Caio Prado, as críticas de Antonio Candido, Sábato Magaldi, Lívio Xavier, textos de Jorge Andrade e muitos outros no Suplemento Literário do Estadão, coordenado pelo professor Décio de Almeida Prado, também ele um professor de Escola Pública. Líamos também Sartre e Simone de Beauvoir, Camus, Merleau Ponty, Arthur Miller, Tennessee Williams e os apreciávamos, mais talvez que autores comunistas e socialistas. Se possível com pitadas generosas de autores existencialistas que Sérgio Milliet traduzia para a Difusão Européia do Livro, capitaneada por um editor francês de esquerda, o discreto Jean-Paul Monteil, cidadão paulistano e dono da Livraria Francesa da rua Barão de Itapetininga... O mesmo que convidou Florestan para dirigir a mais importante coleção de obras renovadoras sobre o Brasil de então, a Corpo de Alma do Brasil. O primeiro título era Mudanfas sociais no Brasil, do próprio Florestan, seguido das obras de Octávio Ianni, Fernando Henrique Cardoso, entre muitas mais: um sopro renovador nas searas em que se cultivava o marxismo, a história, a sociologia... Definia-se a chamada Escola Histórico-sociológica de São Paulo. Rigor, temas fundamentais da História do Brasil, métodos e técnicas modernas de pesquisa postas em prática, leitura mais cuidadosa dos clássicos e sobretudo de Marx, Weber e Mannheim, atitude interdisciplinar, tudo isso marcava o novo horizonte intelectual que se desenhava então. E que viera para ficar. Uma nova postura, enfim.

Era esse o espirito da Faculdade de Filosofia em várias de suas disciplinas e não só exclusivo das Ciências Sociais e Humanas. Talvez seja esse espirito que 
Florestan representa em sua versão mais radical, mais combativa, sobretudo no que diz respeito ao papel dos intelectuais na transição para a democracia. Se foi ele plástico e bastante eclético em suas opções teóricas parà elaborar um marxismo inovador, por assim dizer, brasileiro, sempre foi intransigente em suas firmes determinações políticas. Sobretudo no tocante à escola, ao ensino, à pesquisa $\mathrm{e}$ aos serviços públicos. Sentimento trágico e quase premonitório num país como o nosso, numa universidade como a nossa: foi por imperícia e falta de zelo que viria a falecer, em hospital da USP, como se constatou.

Para os pesquisadores da geração intermediária que ajudaram a criar este Instituto, a presença de Florestan tornou-se marcante também por ter posto sempre em discussão o papel do novo intelectual socialista, que deve ser a um só tempo rigoroso, eclético e combativo. Com isso, distanciava-se de um certo tipo histórico de militante comunista algo esquemático e simplista, que via a história de maneira reduzida, em etapas a serem cumpridas necessariamente. Suas pesquisas nos liberavam para um outro olhar sobre a História e as Ciências Humanas. E tanto mais quanto conhecia e dominava, além dos clássicos da Sociologia e da Antropologia, os clássicos do pensamento marxista. Sua coletânea sobre o pensamento de Marx publicada na coleção Grandes cientistas sociais, é uma referência fundamental neste fim de século, em que a intelectualidade periférica distraída com o pósmodernismo parece ter enterrado antigas utopias. Mas Florestan também dominava os clássicos da historiografia contemporânea, de Huizinga a Febvre, de Labrousse a Braudel, preferindo entretanto os clássicos de Soboul (que o visitara em São Paulo quando de sua cassação); de Dobb e Hill a Hobsbawm (que o considerava um dos maiores cientistas sociais de nosso tempo) e Wallerstein. E cultivava interlocutores em vários quadrantes: Aníbal Quijano no Peru, Stanley e Barbara Stein em Princeton (acolheram-no em sua casa em 1976), Richard Morse em Washington, Magalhães Godinho, Cunhal e Boaventura em Portugal... No Brasil, destaco sua interlocução permanente com Candido, e a referência intensa a obras de Caio e Faoro (o autor de Os donos do poder, cujo título adotou como expressão recorrente). Mas, também, além de seu catedrático Fernando de Azevedo, de Wagley, de Willems e de seu querido Roger Bastide, citava Sérgio Milliet, Paulo Duarte e sobretudo Herbert Baldus, gente de uma época em que política cultural era coisa séria. Hoje, passado o tempo, creio que foi o francês abrasileirado Bastide quem lhe abriu, com Candido, as comportas da vida intelectual universitária concreta no campo da pesquisa.

Florestan deixa algo que é fundamental: a lembrança de que a discussão sobre a requalificação do trabalho cientifico e intelectual deve ser sempre e sempre reproposta, senza fine. Sem o que não há avanço. Tema decisivo, num momento em que a universidade brasileira - que vai muito mal - deve ser repensada 
de alto a baixo, reavaliada e atualizada. Muitas congregações e departamentos deveriam ser rachados ao meio ou até eliminados, cơmo por vezes acontece em universidades de países mais adiantados. Perguntávamo-nos ultimamente: será que o departamento é de fato a unidade básica e intocável da organização universitária brasileira? Será verdade, como dizia Anísio Teixeira - outra grande referência na vida de Florestan - que a universidade no Brasil não passa de um aglomerado de congregações que só se reúnem para discutir o orçamento? Essas dúvidas provinham de um cientista social que, diversamente de outros cientistas sociais narcísicos, era exímio crítico de si próprio e das instituições das quais participava, fosse a cadeira de Sociologia, da qual se tornaria catedrático em 1964, fosse a sua querida Faculdade de Filosofia ou seu Partido dos Trabalhadores. Também com amigos fazia a autocritica deles...

Florestan tornava-se assim algo incômodo e áspero para alguns, sobretudo para os inseguros ou oportunistas. Mas respeitava adversários, fossem universitários ou não. Numa conversa sobre a vida parlamentar no Brasil em 1994, lastimava a falta de atenção que a Câmara dispensava ao deputado Roberto Campos, "nosso inimigo", com seus discursos bem-preparados, eruditos e agudos. Embora discordasse radicalmente, Florestan comentava a falta de percepção, e mesmo decoro, de muitos companheiros parlamentares. Imagino que o mesmo deve ter ocorrido com ele não poucas vezes, em sua atuação como deputado, quando teve papel decisivo nas questões ligadas a ciência, tecnologia, educação e saúde, para mencionarmos campos específicos.

Muito já se escreveu sobre o Florestan professor e sobre o pesquisador, mas ainda falta uma boa tese, certamente alentada, sobre o Florestan político, o grande admirador de Lula, o intelectual tão respeitado por seus companheiros do PT e também de outras agremiações, como Roberto Freire, por seus colegas combatentes por uma universidade crítica no Brasil, por ter reabilitado o papel do intelectual em nossa vida cultural e política. E mesmo o Florestan político admirado por políticos como o velho Ulysses Guimarães ou o seu amigo e exaluno da antiga Faculdade de Filosofia, o ex-senador Severo Gomes. Severo que muito atuou neste IEA e compartilhou com Florestan, aqui e no Parlamento, algumas teses - não todas - sobre o futuro da Nação.

O senso da História na obra e na ação de Florestan vinha de baixo. Jamais esquecerei o encontro simples mas solene de Florestan com Soboul, o grande historiador da Revolução Francesa autor do Les sans-culottes parisiens à l'an II. Numa visita ritual em 1970 ao cassado, Soboul, o professor da Sorbonne, também de origem modesta e filho da Escola Pública, discípulo do socialista Georges Lefebvre e de Mathiez, impressionara-se com a solidez do conhecimento historiográfico do sociólogo paulistano. Sobretudo sobre sua erudição no tocante aos jacobinos, montagnards e sans-culottes da Revolução Francesa. Ou da 
segunda Revolução, a de 1793, a verdadeira, segundo eles (e nós). Tal erudição não era para mim novidade, pois presenciara a argüição de exame de qualificação por que passara meu professor e amigo Fernando A. Novais, que escolheu precisamente ò rigoroso professor Florestan como argüidor de disciplina complementar para seu doutorado. Um dos debates mais avançados e duros que presenciei, em que o patamar mínimo de discussão eram as obras de Marx, Weber, Pirenne, Maurice Dobb e Eli Heckscher. Nascia o livro clássico de Fernando, Portugal e Brasil na crise do antigo sistema colonial (1777-1808)...

Tal senso de História e da importância dos estudos históricos é que levou seus assistentes Cardoso, Ianni, o saudoso Luiz Pereira, Maria Sylvia, Beisigel e tantos outros a procurar temas fundamentais de nosso passado. Creio que eles participaram de um novo redescobrimento do Brasil, da mesma importância que fôra o da geração de Freyre, Buarque, Caio e, nos anos 50, de Candido, Faoro, Furtado. A preocupação com as historicidades e com a especificidade de nossa formação econômico-social atravessa todos eles, que produziram estudos e ensaios notáveis. O senso histórico de Florestan levou-o a estudar e a compreender não apenas a história dos negros no Brasil e a demolir o mito freyreano da democracia racial, mas a desvendar os mecanismos de montagem da sociedade de classes aqui e, depois, na América Latina. A história dos excluídos não foi para ele apenas um clichê de combate, mas o resultado de sofisticada pesquisa. Procurando compreender os negros e sua exclusão, descobriu - literalmente - a sociedade de classes. E outros tipos de formações societárias, de cunho estamental e de castas, tão essenciais para o estudo de sociedades como as nossas, de asfixiante passado colonial e escravista. Eu diria que sua obra desvenda os mecanismos mais complexos, duradouros, que hoje a chamada História das Mentalidades procura estudar. E como não dizer que as discussões sobre as idéias fora do lugar, na proposta brilhante de Roberto Schwarz, não têm sua origem no livrinho fundamental de Florestan, Subdesenvolvimento e sociedade de classes?

Não se trata nesta breve memória de estudo histórico-bibliográfico, mas impõe-se constatar que os estudos históricos ganharam nova dimensão com várias obras de Florestan, desde seu estudo sobre A função social da guerra entre os Tupinambá até Integraf̧ão do negro na sociedade de classes e Circuito fechado. Em Poder e contrapoder na América Latina Florestan nos advertia para o perigo de uma contra-revolução mundial, indicando em 1981 que uma nova Direita, mais sofisticada, se articulava em escala internacional, Direita que nada tinha a ver, na aparência, com os antigos fascismos. Propondo uma rotação de perspectivas, ele estimulava as esquerdas a se repensarem naquele momento de reorganização mundial. Da atualidade daquela advertência torna-se inútil dizer. Mais diretamente sobre nosso país neste fim de século, as conclusões de $A$ revolução burguesa no Brasil permanecem iluminando a História presente do Brasil e nos colocando em situação de desafio, o que era bem típico de seu autor. Situação desafiadora 
tanto mais dificil quando alguns de seus ex-alunos estão no poder, prestando justa homenagem à memória do mestre, embora correndo o risco de se enredarem na metodologia da Conciliação política e culturạl, velha de mais de um século em nosso país.

Que sua memória seja uma presença e uma companhia. Por certo vamos necessitar dela na longa travessia que nos aguarda, pois o que estamos assistindo é a emergência de uma nopa sociedade civil, com novos parâmetros sócio-culturais e ideológicos. A transição, diversamente do que pensa Alain Touraine, mal começou. Afinal, como dizia o professor Florestan, "naturalmente, existe um antes e um depois. O que se impõe agora examinar com profundidade possível, é o durante" (A revolução burguesa no Brasil, 1974).

Carlos Guilherme Mota, historiador, é professor honorário do Instituto de Estudos Avançados da USP e autor, entre outros livros, de Ideologia da cultura brasileira (Ática).

Palestra feita pelo autor no Ato Presença de Florestan Fernandes, organizado pelo Instituto de Estudos Avançados na Sala do Conselho Universitário da USP em 5 de outubro de 1995. 